\title{
Citizen participation plan for València Parcs de Barri
}

\author{
Asenet Sosa Espinosa, Ana Portalés Mañanós, \\ David Urios Mondéjar, Juan Colomer Alcácer
}

Departamento de Urbanismo. Universitat Politècnica de Valencia. Valencia, Spain

E-mail: assoes@urb.upv.es; anporma@urb.upv.es; umdav@urb.upv.es;

juancolomeralcacer@gmail.com

\begin{abstract}
The multifunctional role of neighbourhood scale parks is vital within the urban system. They are not neutral spaces in terms of the functions attributed to them by the social collectivity. This causes them to be analyzed, evaluated and projected in interdependence with the physical and social environment where they are located or can be located. València parcs de barri is a web platform that arises from a teaching project developed by the Teaching and Research Group TUR (urban planning workshop), within the studies of Degree in Architecture at the Universitat Politècnica de València. It is born worried about the improvement in the project decisions of the neighbourhood parks. It considers that these public spaces have not been designed with sensitivity towards the social function that they fulfil. This social function is established by the daily uses that the population makes and what the park means to them. Among the objectives of this platform are to open the University to society, involve students in a social project and listen to the user. In addition, it is necessary to diagnose and design the parks with and for the subject-user, because this is the true protagonist of the public space. This paper collects the need to establish a plan to be followed by València Parcs de Barri in the coming years. The plan is a road map that defines the strategic lines and phases to be followed in a community based research project, applying the methodologies of participatory action.
\end{abstract}

Keywords: Citizen participation, planning, neighborhood parks, valenciaparcsdebarri

\section{Introduction}

The way to organize the relationships between people and their environment has a lot to do with space-temporal perception of the social community about the convivial environment where the daily interaction between its members takes place.

Taking into account that it is in the "neighborhood", as Lefebvre (1967) pointed out, "where the space and time of the inhabitants take form and meaning within the urban space", the social function that supplies fulfill at this level is vital and therefore also will be that of urban parks on a neighborhood scale. Neighborhood parks, like other urban green spaces "are not qualitatively neutral spaces (...), they are characteristic places, differentiated in their contents and forms, as well as in their ecological, urban and social functions" (Vélez, L. , 2009: 33), so they must be analyzed, evaluated and projected in interdependence with both physical and social environment where it is located or can be located.

This leads us to reflect on the plurifunctional role of parks and specifically the social function they fulfill, specially the neighborhood parks, within the urban system. These are collected in multiple scientific-technical documents that echo on public policies in different European countries. 
Relating the plurifunctional role assumed by these urban spaces and observing the reality of urban-territorial transformation processes occurred in recent years, characterized and noted Verdaguer, C. (2012: 7) by a process of "decision making that has been produced on a great distance from those who are now suffering, and following logics very alien to the needs and desires of citizens", is now more than ever encouraged the participatory action in research, planning and transformation of the coexistence spaces that our cities, in an attempt to break with the traditional top-down decisionmaking. Thus, there is currently a broad social, scientific and institutional consensus in relation to the need and importance of promoting, boost and articulati ng active citizen participation in urban regeneration processes.

This implies a change in the forms of management and administration of the public, as well as reinterpretation of the role of the expert or researcher "who should be able and willing to question their own cognitive framework in the encounter with other interpretations of reality, other visions of the world "(Schlierf et al., 2010: 194), advancing in the democratic task.

\section{The social functions of the park and citizen participation}

Among the social functions that are attributed to urban parks and by extension to those located in neighborhoods we can highlight the following:

a) Articulation of the urban neighborhood: To the extent they constitute points of reference to guide us, acting as "nodes", which makes a localization strategy necessary from the point of view of mobility and accessibility.

b) Way of social integration: Its node function implies otherness, that is, the recognition and shared use between different social strata (age, sex, purchasing power, educational levels, origin, etc.), which have to be studied since their perception of this space and the use attributed to it, as well as the demand for internal equipment thereof, will vary.

c) Supports for citizen participation: Due to their porous nature, they can accommodate multiple uses: sports, education, dissemination of ideas and citizen mobilization actions in favor of improving the quality of life in the neighborhood, fostering social dynamism.

d) Elements of social structure: So far as its physical location, design and plurifunctionality affects or allows to structure the citizen in their knowledge about the urban environment, announcing values that are present in the configuration of the social image of the neighborhood, and in the appearance and attachment in the collective imagination of identification's feelings with the place and even in a hallmark of its own.

From all this derives its democratizing function, which is why it is considered that in its configuration and transformation, social agents and non-associated citizens must participate actively, since they are the consumers and users of the urban public space, enjoying or suffering its functions and dysfunctions.

The active participation of citizens and their groups in collaboration with researchers is aimed at the construction of knowledge collectively, from and with the social bases, so that the neighborhood community, which is the one that daily experiences the neighborhood -unit of reference of the context that occupies us-, enters to form part as a subject in the investigation and not as an object of the same.

This approach to community-based research -Community Based Research- should be accessed by integrating the methodology of participatory action research (IAP), considered "as a method of work that gives meaning to praxis in the field" (Flas Borda (2008), Colmenares (2012)), whose utility is to build participation, working on consensus to reduce conflict and collective unrest.

This vision nurtures the foundations and objectives pursued by the birth of the project 'València parcs de barri', which we address in the next lines.

\section{València parcs de barri platform}

In 2011, within the Degree in Architecture studies that are taught at the School of Architecture of the Politecnic University of València, a teaching project starts from the 


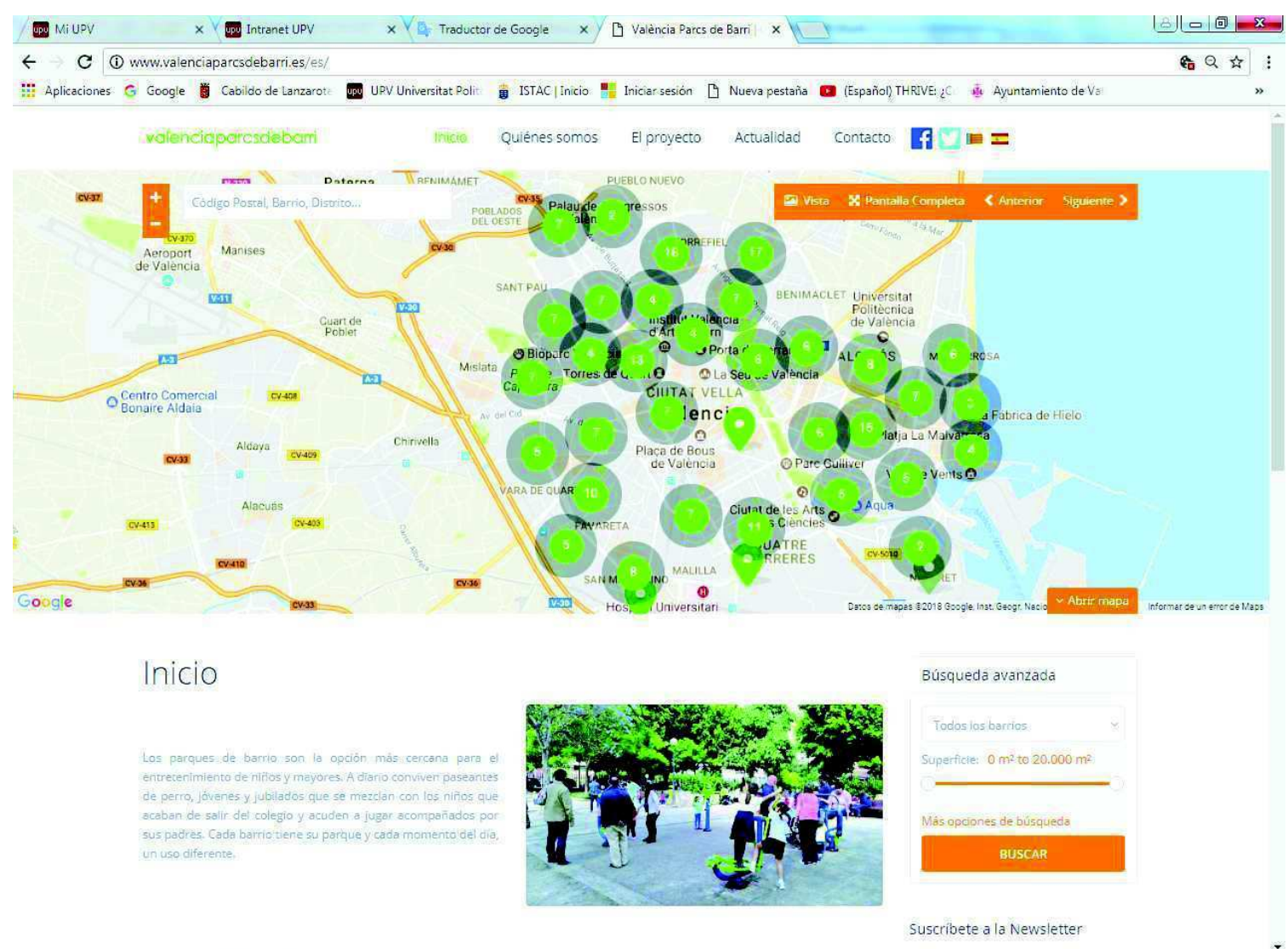

Figure 1.

València Pares de Barri platform.

Source: Image extracted from the web http://www.valenciaparcsdebarri.es/es/

Teaching and Research Group TUR (urban planning workshop) that combines the teaching and learning of the urban form with professional practice and research, that is, while the students learn the tools of the urban architect subsume the theoretical content of the subject to the research praxis, is becoming a scientific observer of the public built space and its social uses.

In the last five years the vast amount of information collected about the neighborhood parks of the municipality of Valencia within this teaching project -about its design, accessibility, equipment, social profiles of users, etc. has enabled València parcs de barri to become a reality.

The web platform valenciaparcsdebarri arises from the concern for improvement in project decisions of neighborhood parks as they are public spaces, considering that most of them suffer from sensitivity in their designs towards the social function they fulfill, marked for the daily uses that their users print

Thus, among the objectives of this platform are to open the University to society, involve students in a social project and listen to the user, diagnosing and designing with and for the subject-user, true protagonist of the public space, so the methodologies and characteristics of participatory action not only make sense, but their knowledge and use becomes necessary throughout the learning and research process.

With these objectives, the direction of this platform raises the need to draw a roadmap where the strategic lines and the phases to follow in a teaching and research project based on the community.

Citizen participation plan for "Valencia parcs de barri'

Based on the principles that drive the emergence of this platform, the objectives it intends to achieve and taking into account the procedures 
it has already put in place, the next step to move forward would be the articulation of a citizen participation plan, referred to its field of action, the neighborhood parks, which combines training as a technician and as a researcher for their students - as part of an educational project in which they are still involved-, while at the same time establishing an action strategy, in the medium term, to integrate a new actor in the project: the subject-user of the neighborhood parks, through the incorporation of new citizen participation mechanisms.

Colmenares, A. (2012: 107) points out that, in a general way, three phases are established within a research-action-training process of this type: 'the diagnosis, the construction of action plans, the execution of said plans and the permanent reflection of those involved in the research, which allows redimensioning, reorienting or rethinking new actions in response to the reflections made.

Thus, the Participation Plan for the area that concerns us must establish the guiding principles that move it and the strategic lines of work that enable the diagnosis involved, from which suggestions for action are built, for the improvement of neighborhood parks, not only from technical perspectives but also incorporating the user into its definition, thus integrating the function attributed to them by the collectivities: diagnosis participated first and, subsequently, design or redesign between the parties involved: technicians, students and citizens.

\section{Participation Plan}

The guiding principles, the strategic lines and the phases to follow will be the following:

\section{Guiding principles:}

They refer to values to be promoted, but they also serve as the basis for the methodologies to be applied.

-Teaching ability: in the teachinglearning process of the future architect in the participatory construction of urban service projects and in the assumption of the values that it implies.

-Open direction: constant interaction

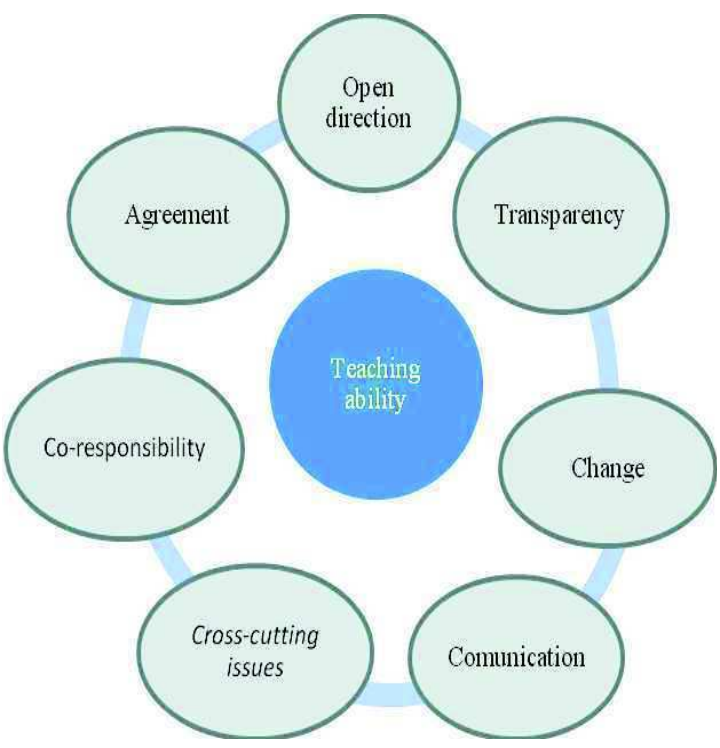

Figure 2.

Guiding principles

institution-citizenship; social commitment with the results of participation; opening and expansion of channels for citizen participation.

-Transparency: constant, accessible and understandable information for different audiences; accountability to citizens; guarantees of response to citizenship.

-Change: incorporation of knowledge of the social bases; continuous learning (review, evaluation and modification of contents, procedures, etc.) in the search for a better quality of life.

-Co-responsibility: conscious and consistent decisions taken together; aware of the interdependencies between the decisions taken in each area.

-Cross-cutting issues: axis of encounter between different topics and problems.

-Communication: transfer of information to the citizen; bidirectionality institutioncitizenship; adaptation of technical-scientific information to the citizen.

-Agreement: opinion, reflection, criticism and tolerance; equity and agreements that benefit the whole; incorporation of different social realities.

Strategic lines:

a) Territorialization. With the purpose of working in a participatory manner, in the more than 200 parks that make up the network of 


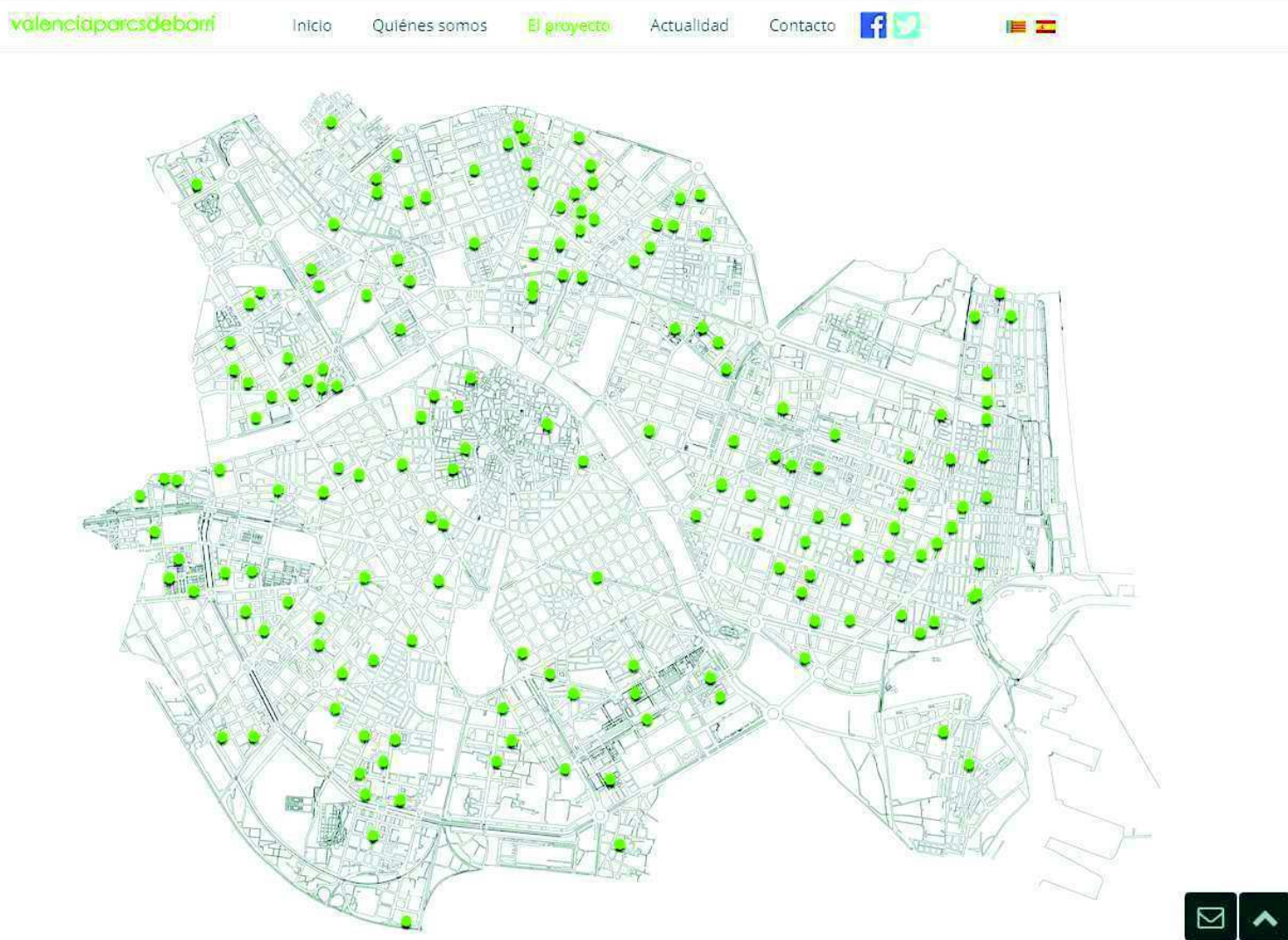

Figure 2.

Map of parks in the neighborhood of Valencia

Source: Image extracted from the web http://www.valenciaparcsdebarri.es/es/

neighborhood parks in the municipality of Valencia, a work program has to be established that defines the criteria and the times to follow for long-term term, cover the entire spectrum of parks in the application of tools for the production of knowledge and proposals for action in a participatory manner. So that it can be coordinated with the teaching rhythms.

b) Educate in action-participation tools. As part of the training of the student body as a researcher and of the citizen as a party involved in it.

c) The participation of citizens as a strategy. Deployments of instruments with which to collect collective knowledge and produce action proposals in a participatory manner using both, quantitative and qualitative social research techniques. The tools to be applied can be organized in the following way:

-Quantitative: surveys and surveys of general topics (currently launched) and specific, in order to know how many people opt for differences, obtain ratings on the park and user profiles.
-Qualitative: application of observational, implicative, reflexive and conversational techniques necessary for the physical and social dimension of the object of study (the neighborhood park), gathering reflections on different aspects from the own experience of the protagonists - the residents-, who they allow to improve the diagnoses and later to open sessions to build action proposals in a collective and participated way.

d) Communication strategy:

-Identification of social actors in the radius of influence of the neighborhood park. The objective is that the information reaches everyone, so different groups (associations, informal groups, etc.) can amplify and disseminate information.

-Establishment of scenarios for participation. Advance in the communication strategy through telematic means already developed and in combination with mechanisms to carry out meetings, with direct face-to-face 
interaction, which strengthen the process and the links.

- Development of a discursive strategy. The communication both by telematic means and in the processes of participation must be done by means of the use of an inclusive and didactic language, that allows that the information is accessible for all the population, always avoiding the use of sexist language.

Phases to follow

The Phases to follow in a community-based research project for València parcs de barri are:

1.Establishment of the objectives of the plan and assumption of regulations in relation to fundamental rights, transparency, good governance and participation.
2.Establishment of an action program for participation with a territorial base, which programs the coverage of the spectrum of neighborhood parks that exist in Valencia.

3.Introduction and involvement of students in the project.

4.Specification, development and application of participatory procedures adapted to general or specific objectives, to the area of influence of the park and to the socio-demographic characteristics of the neighborhood.

5.Analysis of results and technical integration.

6.Dissemination of results.

7.Evaluation and reflection of the process by the intervening agents.

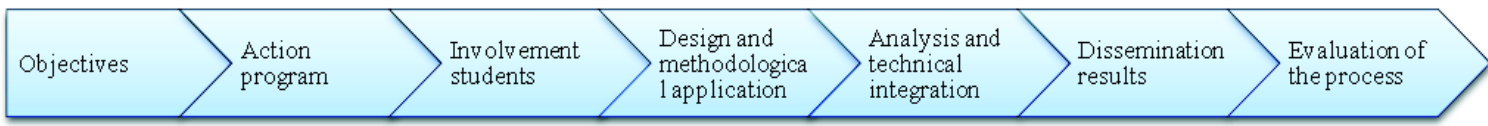

\section{Conclusion}

Neighborhood parks are not qualitatively neutral spaces, but play a multifunctional role in the articulation of everyday urban life and the social integration of its inhabitants in it, covering relevant functions in the construction and maintenance of the social fabric of the neighborhood and by extension from the city. The analyzes and evaluations that direct the design decisions and designs of these public green spaces of our cities, have traditionally suffered from sensitivity towards the social function they fulfill and that is marked by the daily uses that the citizen prints to their physical surroundings. Thus, there are increasing voices that demand the construction of knowledge collectively, where the user-subject enters to be part of the research but not as an object of it. València parcs de Barri, born under a teaching project developed by the Teaching and Research
Group TUR (urban planning workshop), within the Degree in Architecture studies taught at the Politecnic University of València, assumes, within the same Community Based Research, involving its students in a social project of direct interaction with the user of the parks of our neighborhoods, diagnosing and designing with and for him.

In order to reach this goal, and to continue advancing in the task that is proposed, it is now necessary to draw up those strategies that serve as a guide in the coming years, so the next step must be to articulate a plan for citizen participation, coordinated within your project and for your research project about neighborhood parks.

Consequently, said plan departs from the established principles such as: transparency, transversality, co-responsibility, consensus 
and change; together with the establishment of strategies in three directions: education for participatory action, deployment of instruments to work with social agents and citizens, as well as the establishment of scenarios that encourage encounter and participation.

Through this platform you will get a meeting place between technicians-urban planners, students and citizens, giving voice and recognizing the possibilities of contribution of the social bases in the project decisions of the neighborhood parks of the municipality of Valencia, and integrating different interpretations of the same reality.

\section{References}

Colmenares Escalona, A. M. (2012) 'Investigación-acción participativa: una metodología integradora del conocimiento y la acción', Voces y Silencios: Revista Latinoamericana de Educación, Vol. 3, $\mathrm{n}^{\mathrm{o}} 1$, 102-115.

Montañés Serrano, M. (2009) Metodología y técnica participativa. Teoría y práctica de una estrategia de investigación participativa. Barcelona, Editorial UOC.

Schlierf, K., Boni A. and Lozano J.F. (2010) 'La transferencia de tecnología participativa desde la Universidad: hacia un cambio tecnológico', in Martínez, M. (ed.) Aprendizaje, servicio y responsabilidad social de las Universidades (OCTAEDROICE, Barcelona) 193-217.

Vélez Restrepo, L. A. (2009) 'Del parque urbano al parque sostenible. Bases conceptuales y analíticas para la evaluación de la sustentabilidad de parques urbanos', Revista de Geografía Norte Grande, no 43, 31-49.

Verdaguer Viana-Cárdenas, C., and Velázquez Valoria, I. (2012) 'La ciudad de abajo arriba. Aportaciones para la práctica y la teoría del urbanismo participativo', Hábitat y Sociedad, $n^{\circ} 4,7-11$. 